\title{
REMOVING WASTE WHILE PRESERVING SLACK: THE LEAN AND COMPLEXITY PERSPECTIVES
}

\author{
Tarcisio A. Saurin ${ }^{1}$
}

\begin{abstract}
In complex socio-technical systems such as construction projects, the lean emphasis on waste reduction can contribute to the depletion of necessary slack for managing unexpected variability. This risk is amplified by the absence of a solid lean theory on slack and on how to manage the trade-off between slack and efficiency. Furthermore, lean focuses on managing slack in terms of time and inventories. Thus, a broader approach that accounts for a wide variety of slack resources is necessary. In this paper, the complexity science's and lean's views of slack are laid down and compared based on eleven criteria. Commonalities and conflicts between both approaches are identified, and proposals for future research related to slack management in lean complex systems are presented.
\end{abstract}

Keywords: Slack, buffers, complexity, waste, lean.

\section{INTRODUCTION}

As lean production (LP) has spread to several sectors, it has more and more been applied in the so-called complex socio-technical systems (CSSs), which are known for characteristics such as variability and a large number of elements in dynamic interactions (Perrow, 1984). The construction industry is one of these CSSs in which LP has been used, involving a similar set of principles and a set of practices tailored to the sector, known as lean construction (LC). Nevertheless, drawbacks of using lean in CSSs have been pointed out by several studies. For instance, the decision of what counts as value and waste is not straightforward in CSSs, given the multitude of clients and conflicting requirements (Browning and Heath, 2009).

In fact, regardless of positive results, there are many accounts of LP in CSSs which fall short of expectations, sometimes not paying back, worsening working conditions, simply moving waste from one location to another, and creating other undesired side-effects - e.g. public hospitals in Canada (Moraros et al., 2016), public service in the UK (Radnor and Osborne, 2013), and the production of the F-22 fighter (Browning and Heath, 2009). While reports of unexpected or undesired results of LC are not so common, this does not mean they have not occurred. It is possible that undesired side-effects are less likely in construction due to the loosely-coupled nature of most processes, which offers intrinsic slack that cannot be easily removed through lean.

Slack is useful for absorbing variability from different sources, and it is focused on this paper. In LC, the use of the term "buffer" is more common than slack, and it has been

\footnotetext{
${ }^{1}$ Associate Professor, Industrial Engineering and Transportation Department. Federal University of Rio Grande do Sul (UFRGS), Porto Alegre, RS, Brazil, saurin@ufrgs.br
} 
addressed by many studies. Alves and Tommelein (2004) define buffers as resource cushions (e.g. money, time, materials, space), used to protect processes against variation and resource starvation. Russel et al. (2012) acknowledge four main types of buffers in construction: inventory, time, capacity, and plans. In the present paper, the term slack is preferred over the term buffer, as the discussion has implications for other sectors, it is not focused on any specific type of resource, and there is a fairly long research tradition on the management of slack, especially in organizational science (e.g. Sharfman et al., 1988). Also, when "lean" is used in isolation in this paper, it makes reference to both LC and LP.

At a cursory view, lean and complexity science (CS) appear to be in conflict regarding their approach on slack. On the one hand, the lean emphasis on eliminating waste can lead to the removal of slack, which cannot always be easily distinguished from waste. This makes systems tightly-coupled, increasing interactive complexity. On the other hand, CS stresses the need for providing slack so as the system can adjust its performance to both expected and unexpected variability (Perrow, 1984).

This paper presents and compares the lean and CS perspectives on slack, shedding light on research and practical gaps. It is assumed that both views need and can be reconciled, from a theoretical viewpoint. The need assumption is grounded on the previously mentioned increasing use of lean in CSSs. The can assumption is based on the empirical fact that many companies from construction and other complex sectors successfully use lean, which suggests they effectively balance the trade-off between slack and efficiency (Marley et al., 2014). This is a sub-class of the more generic efficiency-thoroughness trade-off, which is ubiquitous in

CSSs and usually managed by means of approximate adjustments by front-line staff (Hollnagel, 2012).

\section{WHAT IS SLACK?}

Slack means available spare resources, of any sort, which can be called on in times of need (Fryer, 2004). Such spare resources do not necessarily imply extra or idle resources, as they may account for existing and strictly necessary resources that may be relocated and used in different ways as needed. Underlying that definition is the notion that virtually any resource can become slack in a certain context: if not by design or opportunistic intentional use, chance can play a role for transforming a resource into slack.

\section{LEAN VIEW OF SLACK}

LP theory and practice usually refers explicitly to slack only in terms of time and inventory of materials. As to time, slack is normally embedded in the calculation of process efficiency, which is always lower than $100 \%$ due to inevitable wastes and mandatory work stoppages, such as time for meals. As to inventories, the practice of designing safety stocks and work-inprocess is the usual means of accounting for slack (Smalley, 2004). However, excessive stock is seen by LP as detrimental since the effects of disruptions will not be immediately visible, and thus there will be no pressure to control their underlying causes (Liker, 2004). In other words, excessive stock implies a high threshold for detecting variability. As to LC, concerns with slack of work-in-process and time seem to be prominent (Gonzalez et al., 2006). This can be due to the project nature of construction, in which a large number of design and production 
tasks need to be synchronized in space-time, while demand for raw materials is not as uncertain and variable as in manufacturing.

Another lean assumption is that slack can be gradually reduced as the system becomes more stable and wastes are eliminated. This is one of the reasons why Spear and Bowen (1999) refer to (perhaps large) inventories as "countermeasures" in lean systems. Furthermore, if a process easily and consistently produces the desired outputs, lean experts may interpret this as a warning that there are excessive slack resources, which probably could be reduced in the quest for efficiency. In order to empirically test whether the slack size is excessive, localized experiments of slack reduction can be made, in order to force the emergence of wastes and stimulate "creative tension" (Womack and Jones, 1998).

Of course, lean also deals less explicitly with slack in many other dimensions, such as: (i) the use of multifunctional workers and cross-training, which helps to deal with variations in demand and absenteeism (Liker, 2004); (ii) the use of cognitive slack (e.g. due to teamwork) and the consideration of several alternatives for solving complex-problems, delaying the final decision to the last possible moment (Shook, 2008); and (c) the "help chain" concept (Spear and Bowen, 1999), which is a standardized routine for the identification and solution of abnormalities. The help chain is triggered by a visual device (andon, in lean jargon) to request help from support areas, which in turn should go to the requested location, discuss a solution jointly with workers and produce organizational learning.

Regardless of the aforementioned concerns with slack, production pressures and the lean stress on waste control are likely to encourage practitioners to favor efficiency over slack when trading-off both. Moreover, such balance of the trade-off may occur as a result of myopic yet very common applications of lean for cost-cutting in the short-term. While this approach is not recommended by lean theorists, the practical appeal of lean as a source of improved productivity makes it a potentially dangerous tool in terms of depleting necessary slack.

\section{COMPLEXITY SCIENCE VIEW OF SLACK}

CS recognizes unpredictability as a key property of CSSs, and thus it tends to view slack as an asset. Slack makes systems loosely-coupled (Perrow, 1984), offering time and other resources to support performance adjustment. Moreover, due to slack, agents in a CSS may realize they are consuming safety margins and recover control before the occurrence of irreversible losses (Rasmussen, 1997). Thus, visibility of the status of slack resources (e.g. availability and amount) is essential in order to support its management.

However, CS also recognizes the role of dynamic interactions between system elements. As a result, slack itself may introduce vulnerabilities due to the creation of new possibilities for undesired and unexpected interactions (Perrow, 1984). For instance, slack can increase systems' opaqueness, disguising small changes and latent hazards which may have non-linear effects. Furthermore, CS recognizes that scarcity of resources is a natural tendency in CSSs, due to continuous performance adjustments (i.e. resilience) by multiple agents, in search of better performance (Dekker, 2011).

It is also worth noting that tight-couplings, either in linear or complex systems, do not necessarily imply absence of slack and impossibility of adaptation. Assembly lines in lean manufacturing plants illustrate this point: although there may be no work-in-process inbetween workstations (i.e. they are tightly-coupled and there is continuous flow), 
abnormalities can be managed through off-line slack, such as safety stocks and the use of a help chain (Liker, 2004).

Complexity science also offers the insight that slack cannot be completely eliminated from a CSS. This applies to slack that equates to waste that cannot be reduced below a certain threshold, at least given known and available technologies. In these cases, all that designers can do is to move waste to a place where it can be less harmful. This type of waste is associated with interactions which are vital for system survival: if the interactions are eliminated the system ceases to produce its outputs. In a construction project, an example of waste and interaction of this type may be a project manager who, himself, orders materials from suppliers. While this activity is waste and cannot be eliminated, it could be in principle less serious if carried out by an administrative worker rather than by the project manager. By contrast, other interactions can be eliminated through design. Thus, waste and slack that cannot be completely designed out account for interactions essential for system survival and that cannot be eliminated given existing resources.

\section{Tight AND LOOSE-COUPLINGS: RELATIONSHIPS WITH SLACK}

CSSs are known for tightly-coupled processes, which means that failures may propagate quickly and in unexpected ways (Perrow, 1984). By contrast, loosely-coupled systems can afford for failures, as there is substantial slack, which is often intrinsic to the system's nature (Perrow, 1984). Regardless of the widespread academic use of the tight-loose coupling analogy, and its relationship with slack, this concept is hardly operationalized and graphically represented. In this section, the Functional Resonance Analysis Method - FRAM (Hollnagel, 2012) is tentatively used in order to make sense of this concept. The FRAM is a method for the modelling of CSSs, which involves: (i) the identification and description of the functions performed by the system, according to the six aspects of each function (input, output, precondition, resource, control, and time); (ii) the analysis of the variability of the outputs of each function, and (iii) the analysis of how the functions interact between themselves; the assumption is that outputs of functions are used by other functions, thus establishing couplings between them (Hollnagel, 2012). These characteristics of the FRAM allow a functional description of CSSs, focusing on work-as-done by front-line workers rather than on work-as-imagined by others.

A generic FRAM model of a portion of a construction project is presented in Figure 1, showing how work packages are interrelated with planning functions and functions that deploy slack. Figure 1 can support a risk assessment, envisioning possible scenarios based on existing planning. According to this Figure, the variability of the outputs of three managerial functions < plan work packages look-ahead $>$, < plan work packages short-term $>$ and $<$ provide resources $>$ may propagate to the operational functions $<$ work package $A>$ and $<$ work package $B>$. Variability of the planning functions could involve, for instance, the short-term scheduling of work packages which did not have all constraints removed at the look-ahead level. In turn, variability of the work package functions triggers two other functions that deploy slack resources - these could be, for example, the planning of overtime work, and the assignment of additional workers. The outputs of the planning functions could also provide slack in terms of time to the work packages. In this case, there would be a coupling linking the output of the planning function to the time aspect of the work package function. As such, in Figure 1, work 
packages $\mathrm{A}$ and $\mathrm{B}$ are loosely coupled with work package $\mathrm{C}$, which is a downstream function. In turn, work package $\mathrm{C}$ is tightly coupled with work package $\mathrm{D}$, due to the absence of a slack function related to C. For future studies, it is proposed that, for any given instantiation like Figure 1, an overall score of the variability and slack associated with functions be estimated and compared. The greater the difference between the slack and the variability score (i.e. slack - variability), the more loosely-coupled the system will be.

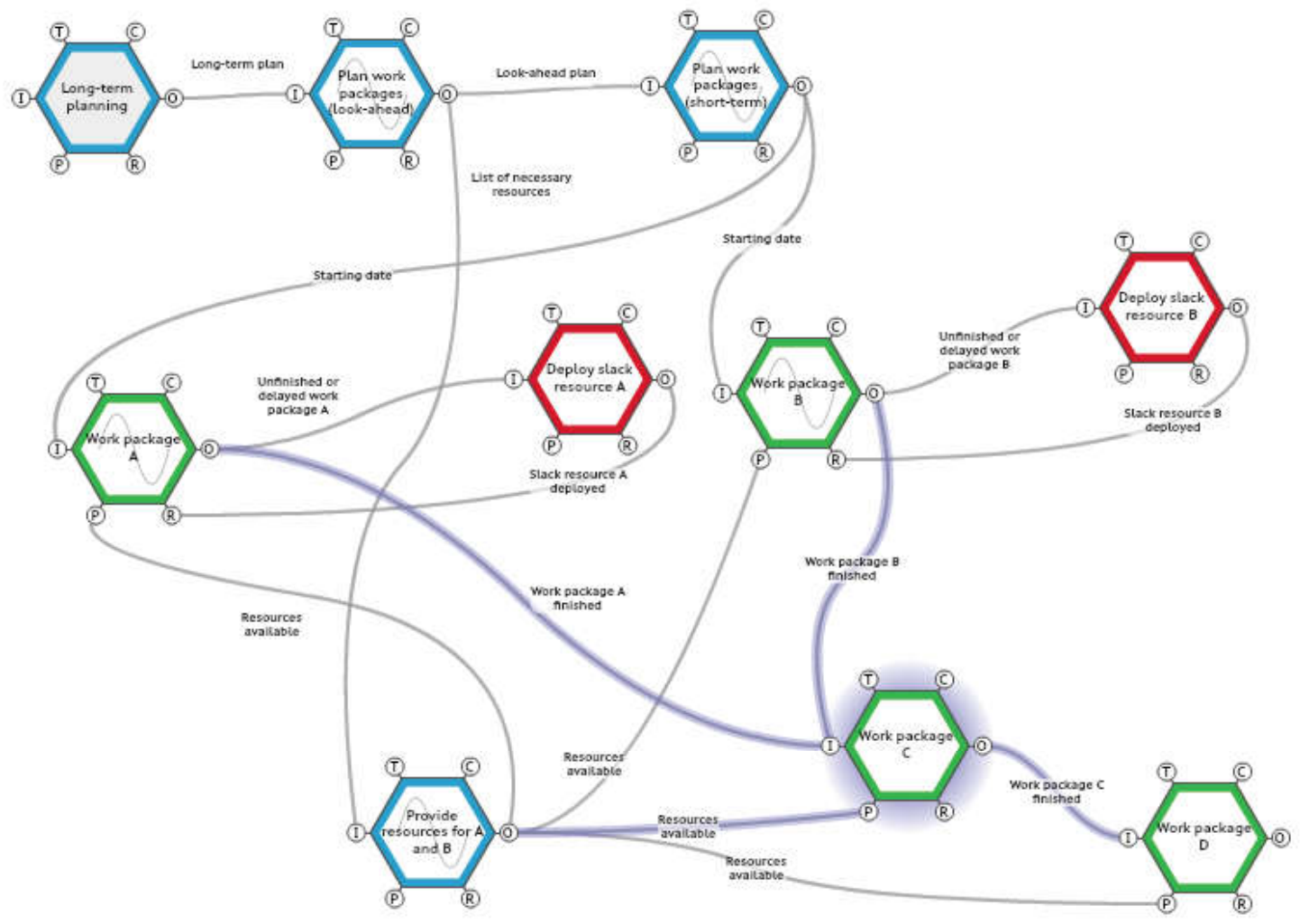

Figure 1: Example of a generic FRAM model in construction. Notes: (i) hexagons represent functions (blue = planning functions, red $=$ function that deploy slack resources, green $=$ work packages); (ii) waves inside hexagons indicate the output of the function has substantial variability; (iii) lines in-between functions represent couplings; (iv) (tight) couplings of work package $\mathrm{C}$ are highlighted

\section{COMPARING THE LEAN AND COMPLEXITY VIEWS OF SLACK}

Table 1 summarizes the comparison between the lean and complexity views of slack, based on criteria for classifying slack resources proposed by Saurin (2015).

Table 1: Comparison of the lean and complexity views of slack 


\begin{tabular}{|c|c|c|}
\hline $\begin{array}{l}\text { (1) Belief regarding the role of } \\
\text { slack }\end{array}$ & $\begin{array}{l}\text { Slack is costly and the need for it arises } \\
\text { from waste and variability: the aim is to } \\
\text { streamline processes so as slack can be } \\
\text { gradually reduced. }\end{array}$ & $\begin{array}{l}\text { Substantial and unpredictable variability are } \\
\text { inevitable in CSSs, and slack offers protection } \\
\text { against these. Safety is a more important value } \\
\text { than efficiency. }\end{array}$ \\
\hline $\begin{array}{l}\text { (2) Belief regarding the nature } \\
\text { of variability }\end{array}$ & $\begin{array}{l}\text { Variability is essentially a hindrance, since } \\
\text { it contributes to waste. Some lean } \\
\text { practices can reduce variability (e.g. } \\
\text { housekeeping), while others require low } \\
\text { variability in order to be effective (e.g. } \\
\text { pull production) }\end{array}$ & $\begin{array}{l}\text { Variability, especially by front-line workers } \\
\text { when making decisions under uncertainty and } \\
\text { scarcity of resources, can be an asset. CSSs } \\
\text { have a high minimum variability threshold, } \\
\text { which cannot be reduced through design and } \\
\text { management (Hollangel, 2012). }\end{array}$ \\
\hline (3) Origin: how slack arises & $\begin{array}{l}\text { It must be designed into the system, and } \\
\text { can be created through waste reduction } \\
\text { (e.g. by reducing excessive inventories, } \\
\text { slack of space and money can be created) }\end{array}$ & $\begin{array}{l}\text { Slack must be designed into the system, and it } \\
\text { can also arise from self-organization }\end{array}$ \\
\hline $\begin{array}{l}\text { (4) How slack evolves over } \\
\text { time }\end{array}$ & $\begin{array}{l}\text { The continuous improvement cycle (i.e. } \\
\text { PDCA) should be used to adjust the size } \\
\text { and location of slack resources over time }\end{array}$ & $\begin{array}{l}\text { The behavior of CSSs is based on their past } \\
\text { history and the corresponding feedback } \\
\text { (Dekker, 2011). Thus, CSSs may learn over } \\
\text { time how to manage slack }\end{array}$ \\
\hline $\begin{array}{l}\text { (5) Interactions: what triggers } \\
\text { the deployment of slack } \\
\text { resources and how these } \\
\text { interact with other processes }\end{array}$ & $\begin{array}{l}\text { Abnormalities of any sort may trigger the } \\
\text { deployment of slack resources. The help } \\
\text { chain is a tool that illustrates how lean } \\
\text { deals with this criteria }\end{array}$ & $\begin{array}{l}\text { Variability of the outputs of functions triggers } \\
\text { the use of slack resources. The FRAM can be } \\
\text { used for modelling how functions that deploy } \\
\text { slack resources interact with other functions }\end{array}$ \\
\hline $\begin{array}{l}\text { (6) Typical slack resources } \\
\text { stressed by theory }\end{array}$ & $\begin{array}{l}\text { Time and inventories of parts (e.g. } \\
\text { finished products, raw materials, semi- } \\
\text { processed products). }\end{array}$ & $\begin{array}{l}\text { No clear stress on any specific resource. } \\
\text { Literature mentions time, redundant equipment, } \\
\text { and cognitive diversity, among others. }\end{array}$ \\
\hline $\begin{array}{l}\text { (7) Concerns with side-effects } \\
\text { of slack }\end{array}$ & Slack hides waste & $\begin{array}{l}\text { Slack interacts with other elements of the } \\
\text { system, and this can trigger undesired emergent } \\
\text { phenomena. }\end{array}$ \\
\hline $\begin{array}{l}\text { (8) Concerns with } \\
\text { quantification: how much is } \\
\text { enough? }\end{array}$ & $\begin{array}{l}\text { A number of industrial engineering } \\
\text { methods can be used to calculate process } \\
\text { efficiency and the size of inventories, } \\
\text { explicitly stipulating an amount of slack }\end{array}$ & $\begin{array}{l}\text { There are no widely accepted and available } \\
\text { tools for quantifying slack. Also, from a } \\
\text { constructivist perspective that permeates some } \\
\text { CS research (e.g. Dekker, 2011), what counts } \\
\text { as sufficient slack is a social construction, } \\
\text { instead of an objective fact. }\end{array}$ \\
\hline $\begin{array}{l}\text { (9) Concerns with giving } \\
\text { visibility to slack }\end{array}$ & $\begin{array}{l}\text { It should be possible to identify at a glance } \\
\text { the status of resources in general. } \\
\text { Visibility of slack viewed as waste (e.g. } \\
\text { idle workers due to unbalanced cycle } \\
\text { times) is also stressed, in order to create } \\
\text { pressure for its elimination. }\end{array}$ & $\begin{array}{l}\text { While the need for visibility is emphasized by } \\
\text { literature, it does not offer practical tools and } \\
\text { principles such as those promoted by lean }\end{array}$ \\
\hline $\begin{array}{l}\text { (10) Concerns with } \\
\text { consumption of slack }\end{array}$ & $\begin{array}{l}\text { Consuming slack, even if unexpectedly, is } \\
\text { not necessarily a major issue. If the system } \\
\text { halts because of this, it creates pressure for } \\
\text { improvement. }\end{array}$ & $\begin{array}{l}\text { There is concern with consumption of slack, } \\
\text { especially from efficiency pressures that create } \\
\text { "normalized deviances"' (Dekker, 2011). As } \\
\text { such, less and less slack may become the } \\
\text { normal state of the system. }\end{array}$ \\
\hline $\begin{array}{l}\text { (11) Typical variability sources } \\
\text { that slack should withstand }\end{array}$ & $\begin{array}{l}\text { Demand and supply, inefficiencies in } \\
\text { general (e.g. defects, delays, etc.) }\end{array}$ & $\begin{array}{l}\text { Variability that impacts on safety and threaten } \\
\text { the system's existence is stressed by CS } \\
\text { literature }\end{array}$ \\
\hline
\end{tabular}

Table 1 suggests that: (i) these two views are potentially in conflict regarding criteria 1 and 2 (beliefs on the nature of slack and variability), which indicates the need for explicitly managing the trade-off between slack as waste and slack as protection - instead of being a problem, the joint use of both views can be useful since it encourages explicit and balanced decision-making; (ii) lean offers practical tools for dealing with criteria 4 (evolution), 5 (interactions), 8 (quantification), and 9 (visibility); the use of these tools provide data that can be interpreted from a complexity perspective; (iii) CS offers a practical tool (i.e. the FRAM) to address criteria 4; and (iv) CS takes a broader view of the slack concept, not emphasizing specific types of resources and sources of variability. Overall, CS seems to offer a stronger theoretical background, while lean offers a more practical approach, regardless of being fairly limited to certain resources and variability types. 


\section{CONCLUSIONS}

While slack is a key concept for both LP and LC, it has been underexplored by researchers from both disciplines. The management of slack may be interpreted as a dimension of project risk management, since it involves a ubiquitous trade-off in construction projects, namely the extent to which variability should be protected without compromising efficiency. This paper offered insights into the said management, by comparing the lean and CS perspectives of slack. Lean assumes that a portion of slack is unnecessary, arising from clear-cut waste that can be eliminated without relevant negative side-effects. Lean also recognizes that not all wastes can be removed given existing conditions, and therefore it provides countermeasures to deal with abnormalities. This "countermeasure" view conveys that slack is fundamentally a drawback, and it may be eventually eliminated as a result of the lean quest for perfection. Conversely, CS asserts that in truly CSSs the emphasis should be on coping with variability and thus slack tends to be seen as protection. CS also warns against side-effects arising from the introduction of slack itself. Moreover, a complexity inspired tool, the FRAM, stands out as a tool for modelling interactions between slack and processes in construction projects and elsewhere.

As to future research, it is proposed: (i) the development of tools for supporting the design and evaluation of a broad range of slack resources over all phases of construction projects, since the design phase; (ii) the development of explicit and operational guidelines for supporting decision-making regarding the trade-off between slack as protection and as waste; and (iii) the investigation of how existing LC practices, such as the Last Planner and BIM, address or could address the management of slack.

\section{ACKNOWLEDGMENTS}

This research work was funded by Financiadora de Estudos e Projetos (FINEP), and it is part of a research project entitled "Technologies for Sustainable Construction Sites for Social Housing" (CANTEC-HIS).

\section{REFERENCES}

Alves, T., and Tommelein, I.D. (2004). Simulation of Buffering and Batching Practices in the Interface Detailing-Fabrication-Installation of HVAC Ductwork. Proc. 12nd Ann. Conf. of the Int'l. Group for Lean Construction, Elsinore, Denmark.

Browning, T., and Heath, R. (2009). Reconceptualizing the effects of lean on production costs with evidence from the F-22 program. Journal of Operations Management, 27, pp. 23-44.

Dekker, S. (2011). Drift into Failure: From Hunting Broken Components to Understanding Complex Systems. CRC Press, Boca Raton.

Fryer, P. (2004). Running an organization along complexity lines. In: Kernick, D. (Ed.) Complexity and Healthcare Organization: a view from the street. Radcliffe Medical Press, Abingdon, pp. 289-298.

Gonzalez, V., Alarcon, L.F., and Gazmuri, P. (2006). Design of Work in Process Buffers in Repetitive Building Projects: A Case Study. Proc. 14th Ann. Conf. Int'l.Group for Lean Construction, Santiago, Chile, pp. 10-20. 
Hollnagel, E. (2012). FRAM: the Functional Resonance Analysis Method: Modeling complex socio-technical systems. Ashgate, Burlington.

Liker, J. (2004). The Toyota Way: 14 management principles from the world's greatest manufacturer. McGraw-Hill, New York.

Marley, K., Ward, P., and Hill, J. (2014). Mitigating supply chain disruptions - a normal accident perspective. Supply Chain Management: an international journal, 19(2), pp. 142152.

Moraros, J., Lemstra, M., and Nwankwo, C. (2016). Lean interventions in healthcare-do they actually work? A systematic literature review. International Journal for Quality in Health Care, 28(2), pp. 150-165.

Perrow, C. (1984). Normal Accidents: living with high-risk technologies. Princeton University Press, Princeton.

Radnor, Z., and Osborne, S. (2013). Lean: a failed theory for public service? Public Management Review, 15(2), pp. 265-287.

Rasmussen, J. (1997). Risk management in a dynamic society: a modeling problem. Safety Science, 27(2/3), pp.183-213.

Russell, M., Howell, G., Hsiang, S., and Liu, M. (2012). Causes of time buffer in construction project task durations. Proc. 20th Ann. Conf. Int'l. Group for Lean Construction, San Diego, USA.

Saurin, T.A. (2015). Classification and assessment of slack: implications for resilience. In: Proc. $6^{\text {th }}$ Resilience Engineering Symposium, Lisbon. Available at <www.resilienceengineering-association.org>.

Sharfman, M., Wolf, G., Chase, R., and Tansik, D. (1988). Antecedents of organizational slack. The Academy of Management Review, 13(4), pp. 601-614.

Shook, J. (2008). Managing to Learn: using the A3 management process to solve problems, gain agreement, mentor and lead. Lean Enterprise Institute, Cambridge.

Smalley, A. (2004). Creating Level Pull. Lean Enterprise Institute, Cambridge.

Spear, S., and Bowen, H. (1999). Decoding the DNA of the Toyota Production System. Harvard Business Review, pp. 97-106.

Womack, J., and Jones, D. (1998). Lean Thinking: Banish Waste and Create Wealth in your Corporation. Simon and Schuster, New York. 